\title{
Light to moderate intake of alcohol, drinking patterns, and risk of cancer: results from two prospective US cohort studies
}

\author{
Yin Cao, ${ }^{1}$ Walter C Willett,1,2,3 Eric B Rimm, 1,2,3 Meir J Stampfer, ${ }^{1,2,3}$ Edward L Giovannucci1,2,3
}

'Department of Nutrition, Harvard TH Chan School of

Public Health, Boston, MA

02115, USA

2Department of Epidemiology, Harvard TH Chan School of

Public Health, Boston, MA, USA

${ }^{3}$ Channing Division of Network

Medicine, Brigham and

Women's Hospital and Harvard

Medical School, Boston, MA

USA

Correspondence to:

E L Giovannucci

egiovann@hsph.harvard.edu

Additional material is published online only. To view please visit

the journal online (http://dx.doi. org/10.1136/bmj.h4238)

Cite this as: $B M J$ 2015;351:h4238 doi: 10.1136/bmj.h4238

Accepted: 28 July 2015

\section{ABSTRACT \\ OBJECTIVES}

To quantify risk of overall cancer across all levels of alcohol consumption among women and men separately, with a focus on light to moderate drinking and never smokers; and assess the influence of drinking patterns on overall cancer risk.

\section{DESIGN}

Two prospective cohort studies.

SETTING

Health professionals in the United States.

PARTICIPANTS

88084 women and 47881 men participating in the

Nurses' Health Study (from 1980) and Health

Professionals Follow-up Study (from 1986), followed until 2010.

\section{MAIN OUTCOMES AND MEASURES}

Relative risks of cancer.

\section{RESULTS}

19269 and 7571 (excluding non-advanced prostate cancers) incident cancers were documented among women and men, respectively, over 3144853 person years. Compared with non-drinkers, light to moderate drinkers had relative risks of total cancer of 1.02 (95\% confidence interval 0.98 to 1.06) and 1.04 (1.00 to 1.09; $\left.P_{\text {trend }}=0.12\right)$ for alcohol intake of 0.1-4.9 and 5-14.9 g/day among women, respectively. Corresponding values for men were 1.03 (0.96 to 1.11), 1.05 (0.97 to 1.12), and 1.06 ( 0.98 to $\left.1.15 ; P_{\text {trend }}=0.31\right)$ for alcohol intake of 0.1-4.9, 5-14.9, and 15-29.9 g/day, respectively. Associations for light to moderate drinking and total cancer were similar among ever or never smokers, although alcohol consumption above moderate levels (in particular $\geq 30 \mathrm{~g} /$ day) was more strongly associated with risk of total cancer among ever smokers than never smokers. For a priori defined alcohol related cancers in men, risk was not appreciably increased for light and moderate drinkers who never smoked $\left(P_{\text {trend }}=0.18\right)$. However, for women, even an alcohol consumption of 5-14.9 g/day was associated with increased risk of alcohol related cancer (relative risk 1.13 (95\% confidence interval 1.06 to 1.20$)$ ), driven by breast cancer. More frequent and heavy episodic drinking was not further associated with risk of total cancer after adjusting for total alcohol intake.

CONCLUSION

Light to moderate drinking is associated with minimally increased risk of overall cancer. For men who have never smoked, risk of alcohol related cancers is not appreciably increased for light and moderate drinking (up to two drinks per day). However, for women who have never smoked, risk of alcohol related cancers (mainly breast cancer) increases even within the range of up to one alcoholic drink a day.

\section{Introduction}

Heavy alcohol consumption has been linked to increased risk of several cancers, including cancer of the colorectum, female breast, oral cavity, pharynx, larynx, liver, and esophagus, ${ }^{1}$ and possibly to a higher risk of cancer of the stomach, ${ }^{23}$ pancreas, ${ }^{34}$ lung, ${ }^{35}$ and gallbladder. ${ }^{3}$ However, the association of these cancers with light to moderate drinking (up to one alcoholic drink per day for women and up to two alcoholic drinks per day for men according to the Dietary Guidelines for Americans, 20106) is less clear. ${ }^{7-9}$

Extensive literature has documented the J shaped associations between alcohol intake and a variety of diseases, including multiple cardiovascular outcomes ${ }^{10}$ (such as congestive heart failure, ${ }^{11}{ }^{12}$ and stroke ${ }^{13}$ ) as well as diabetes ${ }^{14}$ and all cause mortality, ${ }^{15}$ and possibly coronary heart disease. ${ }^{16}$ Light to moderate drinkers have a lower risk of these disorders than abstainers, and heavy drinkers are at the highest risk. However, the potential benefits of alcohol consumption have to be weighed against the other possible health risks, and cancer is a major concern. ${ }^{17}$ A recent analysis from the United Kingdom's Million Women Study found that during seven years of follow-up, women who drank seven to 14 drinks per week had a small increase in risk of all cancers (relative risk 1.05, 95\% confidence interval 1.03 to 1.07) compared with drinkers who drank fewer than two drinks per week. ${ }^{7}$ The association between light to moderate drinking and overall cancer risk is less clear in the United States, where light to moderate drinking is more prevalent than in the UK. ${ }^{18}$ The influence of drinking patterns on overall cancer risk is unclear. 
Although the relation between alcohol and cancer has been extensively studied, the role of alcohol independent of smoking has not been settled. Two aspects are particularly important to consider. Firstly, high alcohol drinkers are more likely to smoke-a very strong risk factor for cancer-and although smoking has been adjusted for in analyses, residual confounding may exist. ${ }^{1920}$ Secondly, smoking is the major risk factor for most alcohol related cancers, ${ }^{2122}$ apart from female breast cancer. Thus, in studies that include smokers, the apparent influence of alcohol on cancer could be partly driven by its effect among smokers, and findings might not be generalizable to non-smokers, who now make up the majority of the population. ${ }^{23}$

To address these questions, we aimed to evaluate the association of alcohol consumption-including quantity (in particular light to moderate intake), frequency, and heavy episodic drinking-with risk of cancer in two large cohort studies of US women and men. In addition, we aimed to determine the dose-response relation of alcohol and cancer among never smokers, which would be particularly informative for the general public.

\section{Methods}

Study population

We used two ongoing prospective US cohort studies; the Nurses' Health Study (NHS), including 121700 female nurses aged 30-55 years at enrolment in 1976, and the Health Professionals Follow-up Study (HPFS), including 51529 male health professionals aged 40-75 years at enrolment in 1986. Participants were mailed questionnaires at enrolment and two years thereafter to collect data for demographics, lifestyle factors, medical history, and disease outcomes, and reported updates in dietary intake every four years. The follow-up rates in both cohorts were greater than $90 \%$. The study protocol was approved by the institutional review boards of the Harvard T H Chan School of Public Health and Brigham and Women's Hospital.

\section{Assessment of alcohol consumption}

Information on alcohol consumption was first collected in 1980 in NHS and 1986 in HPFS when participants completed a semiquantitative food frequency questionnaire and reported their average frequency of consumption of specific food and beverage items during the previous 12 months. Alcohol consumption (in grams per day) was calculated as the sum of the daily number of drinks multiplied by the average alcohol content per type of alcoholic beverage ( $12.8 \mathrm{~g}$ of alcohol per $12 \mathrm{oz}$ serving $(355 \mathrm{~mL})$ of beer, $11.3 \mathrm{~g}$ per $12 \mathrm{oz}$ of light beer, $11.0 \mathrm{~g}$ per $4 \mathrm{oz} \mathrm{(118}$ $\mathrm{mL}$ ) of wine, and $14.0 \mathrm{~g}$ per standard serving $(44 \mathrm{~mL})$ of liquor). The portion size for red and white wine was increased to $5 \mathrm{oz}(148 \mathrm{~mL})$ in 2006, and alcohol content was adjusted to reflect the changes. Alcohol intake measured by the food frequency questionnaire was highly correlated with intake calculated from detailed food diaries completed by 173 women and 136 men (Spearman correlation coefficient $=0.90$ for women, 0.86 for men), and correlated with high density lipoprotein levels. ${ }^{24}$ Data for current alcohol consumption were updated in
1984 and 1986 in NHS, and every four years from 1986 to 2006 in both cohorts. We calculated the cumulative average alcohol intake by averaging alcohol consumption over time from 1980 for NHS and 1986 for HPFS to the current questionnaire cycle and updating data when information on alcohol consumption was updated.

Analyses on drinking frequency began with the 1988 questionnaire in NHS and 1986 questionnaire in HPFS when participants were first asked the usual number of days when alcohol was consumed in a typical week. Analyses on heavy episodic drinking started from 1988 when participants were asked the largest number of alcoholic drinks consumed in one day in a typical month $(0,1-2,3-5$, $6-9,10-14$, or $\geq 15$ ). The drinking frequency question was updated in 1996, 2000, and 2004 in NHS; and updated in 1988, 1998, and every two years from 2002 in HPFS. The assessment of heavy episodic drinking was updated in 1988, 1996, 2000, and 2004 in NHS; and updated in 1992, 1996, and every two years from 2004 in HPFS.

\section{Ascertainment of cancer}

In each cohort, participants reported cancer and other disease endpoints in biennial questionnaires. Researchers obtained permission from the study participants to obtain their medical records and pathological reports and abstracted the information on anatomical location, stage, and histological type of the cancer. Confirmed cancers were defined according to ICD-9 (international classification of diseases, 9th revision).

\section{Statistical analysis}

We excluded participants with cancer, implausible energy intakes (reported as $<600$ or $>3600 \mathrm{kcal} /$ day for women, and $<800$ or $>4200 \mathrm{kcal} /$ day for men; $1 \mathrm{kcal}=4.18 \mathrm{~kJ}$ ), or missing alcohol intake at baseline. As the main analysis, we examined cumulative average consumption of alcohol (0, 0.1-4.9, 5-14.9, 15-29.9, 30-44.9, $\geq 45 \mathrm{~g}$ /day) in relation to risk of any type of cancer. Most prostate cancer detected through prostate specific antigen screening is indolent; therefore, we only included participants with advanced or lethal prostate cancer. This group was defined as participants with regionally invasive or metastatic prostate cancer at diagnosis (stages $\geq \mathrm{T} 3 \mathrm{~b}$, N1, or M1), or who developed metastases or died from prostate cancer during follow-up.

Person years of follow-up accrued from the date of return of the 1980 questionnaire in NHS and 1986 questionnaire in HPFS until either the date of diagnosis of any type of cancer, death, or the end of follow-up (June 2010 for NHS and January 2010 for HPFS), whichever came first. We used Cox proportional hazards models with time varying alcohol consumption and covariates to compute hazard ratios as estimates for age adjusted and multivariable adjusted relative risks and 95\% confidence intervals. To control as finely as possible for confounding by age, calendar time, and any possible two way interactions between these two time scales, we stratified the analysis jointly by age in months at start of follow-up and calendar year of the current questionnaire cycle. The time scale for the analysis was months since the start of the current questionnaire cycle, which is equivalent to age in 
months because of the way we structured the data and formulate the model for analysis.

Departures from the proportional hazards assumption was tested by likelihood ratio tests comparing models with and without the interaction terms of age or calendar time by categories of alcohol consumption. We found no significant violation of the proportionality assumption ( $\mathrm{P}>0.05$ for all tests). In addition to risk of total cancer, we also investigated the association with alcohol related cancers (cancer of the colorectum, female breast, oral cavity, pharynx, larynx, liver, and esophagus), as defined by the International Agency for Cancer Research, ${ }^{1}$ and other cancer sites.

We adjusted for the following characteristics:

- Race (white $v$ non-white)

- Height (continuous)

- Body mass index (by quintiles)

- Family history of cancer (yes $v$ no)

- Physical exam (yes $v$ no)

- History of colonoscopy or sigmoidoscopy (yes $v$ no)

- Smoking (pack years in the following categories: never smoker, 1-4.9, 5-19.9, 20-39.9, $\geq 40$ )

- Leisure time physical activity (metabolic equivalent of task hours per week; by quintiles)

- Regular use of aspirin (yes $v$ no)

- Current use of multivitamin (yes $v$ no)

- Total energy intake (by quintiles)

- Red and processed meat intake (by quintiles).

We also adjusted for the prostate specific antigen test (yes $v$ no) among men, and menopause status (premenopause or postmenopause), postmenopausal hormone use (never, past, or current), and use of mammograms (yes $v$ no) among women.

To capture potential confounding by diet, we adjusted for the alternate health eating index (AHEI) $2010 .{ }^{25}$ The index features higher consumption of vegetables (excluding potatoes), whole fruit, whole grains, nuts and legumes, long chain omega 3 fatty acids, and polyunsaturated fat; lower consumption of sugar sweetened beverages, red or processed meat, sodium, and trans fats; and moderate alcohol consumption. Dietary adherence to the AHEI 2010 has been associated with a reduced risk of cardiovascular disease, diabetes, and cancer. ${ }^{26}$ In the present analysis, a modified AHEI 2010 without alcohol consumption was used. All variables including alcohol consumption variables (apart from race and height) were updated from follow-up questionnaires and considered as time varying covariates in the Cox models.

We performed tests for linear trends using alcohol consumption as a continuous variable. In addition to evaluating the trend across all levels of alcohol intake, we also restricted intake to less than $15 \mathrm{~g} /$ day for women and less than $30 \mathrm{~g} /$ day for men, to evaluate the trend within light to moderate alcohol consumption. We used restricted cubic splines to non-parametrically examine the possible non-linear relation between alcohol consumption and risk of cancer or alcohol related cancer. To test for non-linearity, we used the likelihood ratio test, which compared the model with only the linear term to the model with the linear and cubic spline terms. We also examined whether the associations between alcohol and cancer differed by age ( $<65$ years $v$ $\geq 65$ years), body mass index ( $<25 v \geq 25$ ), family history of colorectal cancer or female breast cancer (yes $v$ no), current use of multivitamin (yes $v$ no), regular use of aspirin (yes $v$ no), dietary adherence to AHEI 2010 (median value or over $v$ less than median value), and smoking history (never $v$ ever). Tests for interaction were performed using likelihood ratio tests.

For drinking patterns, we evaluated the association between frequency of drinking, as indicated by how many days alcohol was consumed in a typical week (0, 1-2, 3-4, 5-6, 7); heavy episodic drinking, as assessed by the largest number of alcoholic drinks consumed in one day in a typical month (0, 1-2, 3-5, $\geq 6)$; and risk of cancer. Tests for linear trends were performed using frequency of drinking as a continuous variable, and the median of each category of heavy episodic drinking as a continuous variable.

There were concerns that former heavy drinkers before the initiation of the cohorts may be included in the reference group. Therefore, we conducted sensitivity analyses excluding participants who reported no alcohol intake at baseline but greatly decreased their alcohol intake in the previous 10 years (2922 women, 6406 men). We also conducted analyses including all the non-advanced prostate cancers to the total of all cancers. We evaluated the association between baseline alcohol consumption (1980 in NHS and 1986 in HPFS) and risk of cancer. All analyses were performed using SAS version 9.3, with a two sided significance of $\mathrm{P}<0.05$.

\section{Patient involvement}

No patients were involved in setting the research question or the outcome measures, nor were they involved in the design and implementation of the study. There are no plans to involve patients in dissemination.

\section{Results}

During up to 30 years of follow-up of 88084 women and 47881 men, 19269 and 7571 incident cancers were diagnosed, respectively. Median consumption of alcohol was $1.8 \mathrm{~g} /$ day in women and $5.6 \mathrm{~g} /$ day in men at baseline (1980 in NHS and 1986 in HPFS). Abstainers or heavy drinkers were less likely than light and moderate drinkers to have had a regular physical exam and be screened for colorectal, prostate, or breast cancer (table 1). They also engaged in fewer physical activities and had lower AHEI 2010 dietary scores. Heavy drinkers were more likely to be ever smokers, and had higher pack years of smoking.

Overall, alcohol consumption was significantly associated with increased risk of cancer, for both women $\left(\mathrm{P}_{\text {trend }}<0.001\right)$ and men $\left(\mathrm{P}_{\text {trend }}=0.006\right.$; table 2$)$. Non-parametric regression curves suggested that the dose-response relation were linear ( $P$ for curvature $=0.79$ for women and 0.75 for men), and that the increased risk of cancer appear to be significant at lower levels of alcohol consumption in women than in men (fig 1).

Compared with non-drinkers, relative risks of total cancer for light to moderate drinkers were 1.02 (95\% confidence interval 0.98 to 1.06 ) and 1.04 (1.00 to 1.09) 


\begin{tabular}{|c|c|c|c|c|c|c|}
\hline \multirow[b]{2}{*}{ Characteristic } & \multicolumn{6}{|c|}{ Cumulative average consumption of alcohol (g/day) } \\
\hline & 0 & $0.1-4.9$ & $5-14.9$ & $15-29.9$ & $30-44.9$ & $\geq 45$ \\
\hline \multicolumn{7}{|l|}{ Women } \\
\hline Age (years)* & $58.3(11.1)$ & $59.7(10.8)$ & $59.2(10.7)$ & $60.1(10.5)$ & $58.8(10.3)$ & $58.0(9.9)$ \\
\hline White (\%) & 96 & 98 & 98 & 99 & 99 & 99 \\
\hline Family history of cancer (\%) & 34 & 38 & 38 & 37 & 34 & 33 \\
\hline Height (cm) & $163(6)$ & $164(6)$ & $164(6)$ & $164(6)$ & $164(6)$ & $164(6)$ \\
\hline Body mass index & $26.2(5.2)$ & $25.6(4.7)$ & $24.3(3.8)$ & $23.9(3.6)$ & $24.0(3.8)$ & $24.0(3.9)$ \\
\hline Postmenopause (\%) & 74 & 75 & 75 & 76 & 77 & 77 \\
\hline Current hormone therapy use (\%) & 25 & 30 & 32 & 33 & 27 & 24 \\
\hline Physical examination in past 2 years (\%) & 68 & 74 & 73 & 74 & 68 & 65 \\
\hline History of colonoscopy or sigmoidoscopy (\%) & 31 & 37 & 36 & 36 & 32 & 30 \\
\hline Mammogram in past 2 years (\%) & 66 & 74 & 75 & 76 & 68 & 64 \\
\hline Regular aspirin use (\%) & 39 & 41 & 43 & 45 & 46 & 44 \\
\hline Current use of multivitamin (\%) & 46 & 51 & 52 & 50 & 48 & 48 \\
\hline Physical activity (MET h/week) & $13.5(16.5)$ & $15.8(17.7)$ & $18.0(19.6)$ & $18.1(19.3)$ & $15.7(18.3)$ & $13.7(16.5)$ \\
\hline Never smoker (\%) & 63 & 47 & 34 & 25 & 19 & 18 \\
\hline No of pack years among ever smokers & $25.0(20.7)$ & $21.9(19.0)$ & $22.2(19.1)$ & $26.1(20.8)$ & $33.4(23.5)$ & $38.3(25.6)$ \\
\hline Calorie intake from sources other than alcohol (kcal/day) $\dagger$ & $1648(463)$ & $1653(437)$ & $1611(437)$ & $1586(427)$ & $1524(430)$ & $1555(446)$ \\
\hline Red and processed meat in diet (no of servings/week) & $7.0(4.1)$ & $6.6(3.5)$ & $6.6(3.5)$ & $6.7(3.5)$ & $7.2(3.8)$ & $7.7(4.4)$ \\
\hline Alternate healthy eating index $2010 \neq$ & $44.7(10.0)$ & $45.7(9.5)$ & $46.3(9.2)$ & $45.8(9.1)$ & $43.5(9.1)$ & $41.9(9.3)$ \\
\hline \multicolumn{7}{|l|}{ Men } \\
\hline Age (years)* & $62.2(11.0)$ & $62.6(11.0)$ & $62.7(10.7)$ & $63.3(10.6)$ & $63.5(10.5)$ & $63.0(10.2)$ \\
\hline White (\%) & 87 & 89 & 91 & 92 & 93 & 93 \\
\hline Family history of cancer (\%) & 23 & 27 & 27 & 28 & 25 & 26 \\
\hline Height $(\mathrm{cm})$ & $178(7)$ & $178(7)$ & $178(7)$ & $179(7)$ & $179(7)$ & $179(7)$ \\
\hline Body mass index & $25.9(3.8)$ & $25.9(3.5)$ & $25.7(3.3)$ & $25.7(3.2)$ & $25.7(3.2)$ & $26.0(3.3)$ \\
\hline Physical examination in past 2 years (\%) & 71 & 76 & 77 & 77 & 75 & 72 \\
\hline History of colonoscopy or sigmoidoscopy (\%) & 42 & 52 & 52 & 53 & 48 & 44 \\
\hline Prostate specific antigen test in past 2 years (\%) & 24 & 34 & 35 & 36 & 30 & 26 \\
\hline Regular aspirin use (\%) & 35 & 39 & 42 & 46 & 46 & 44 \\
\hline Current use of multivitamin (\%) & 41 & 46 & 47 & 48 & 45 & 46 \\
\hline Physical activity (MET h/week) & $26.7(29.2)$ & $28.6(27.7)$ & $31.9(28.9)$ & $33.2(30.6)$ & $30.1(29.1)$ & $27.9(27.7)$ \\
\hline Never smoker (\%) & 64 & 54 & 45 & 35 & 27 & 23 \\
\hline No of pack years among ever smokers & $26.6(20.7)$ & $23.3(18.5)$ & $22.4(17.6)$ & $24.0(18.0)$ & $29.1(20.3)$ & $31.7(22.1)$ \\
\hline Calorie intake from sources other than alcohol (kcal/day) $\dagger$ & $1912(579)$ & $1891(549)$ & $1895(545)$ & $1915(540)$ & $1887(547)$ & $1910(543)$ \\
\hline Red and processed meat in diet (no of servings/week) & $6.2(4.8)$ & $6.0(4.4)$ & $6.3(4.3)$ & $6.8(4.3)$ & $7.5(4.7)$ & $8.1(4.9)$ \\
\hline Alternate healthy eating index $2010 \ddagger$ & $47.5(10.8)$ & $48.4(10.2)$ & $48.6(9.9)$ & $47.9(9.5)$ & $45.9(9.5)$ & $44.2(9.4)$ \\
\hline
\end{tabular}

MET $\mathrm{h} /$ week=metabolic equivalent of task hours per week.

${ }^{*}$ All values other than age have been directly standardized to age distribution (in 5-year age group) of all the participants. Mean (SD) was presented for continuous variables. $\dagger 1 \mathrm{kcal}=4.18 \mathrm{~kJ}$.

$\neq$ Without alcohol intake.

for alcohol intake of 0.1-4.9 and 5-14.9 g/day among women, respectively $\left(\mathrm{P}_{\text {trend }}=0.12\right)$. Corresponding values for men were 1.03 (0.96 to 1.11$), 1.05$ (0.97 to 1.12$)$, and 1.06 (0.98 to 1.15) for alcohol intake of 0.1-4.9, 5-14.9, and 15-29.9 g/day $\left(\mathrm{P}_{\text {trend }}=0.31\right)$, respectively. Results were similar if we excluded non-drinkers at baseline (in 1980 for women and 1986 for men) who had greatly decreased their alcohol intake in the previous 10 years (web table S1), or non-advanced prostate cancers were included (web table S2), or baseline alcohol intake (in 1980 for women and 1986 for men) was evaluated instead of the cumulative average (web table S3). All alcohol beverage types showed an association suggesting that the ethanol but not other components of the beverages was the primary factor (web table S4).

The associations between light to moderate drinking and risk of total cancer were similar regardless of smoking history (never or ever smokers). However, alcohol consumption above moderate levels, in particular at least $30 \mathrm{~g} /$ day $\left(\mathrm{P}_{\text {interaction }}=0.06\right.$ for women and 0.11 for men), was more strongly associated with risk of cancer among ever than among never smokers (web table S5, web figs S1 and S2). Joint analysis of alcohol intake and smoking suggested that, compared with alcohol, smoking was a much stronger risk factor for cancer, and independent influence of alcohol, especially in the range of light to moderate drinking, could be minimal (fig 2, web table S6). The association between alcohol and total cancer was not appreciably different by age, multivitamin or aspirin use, AHEI 2010, or family history of breast cancer among women, but was stronger among people with a family history of colorectal cancer (although interactions were not significant; web table S5).

For a priori defined alcohol related cancers (affecting the colorectum, female breast, oral cavity, pharynx, larynx, liver, and esophagus), 9016 and 1611 cases were documented during follow-up among women and men, respectively (web table S7). Breast cancer was the 


\begin{tabular}{|c|c|c|c|c|c|c|c|c|}
\hline & \multicolumn{6}{|c|}{ Cumulative average consumption of alcohol (g/day) } & \multirow{2}{*}{$\begin{array}{l}P_{\text {trend }} \\
\text { (all)§ }\end{array}$} & \multirow{2}{*}{$\begin{array}{l}P_{\text {trend }} \\
\text { (moderate) }\end{array}$} \\
\hline & 0 & $0.1-4.9$ & $5-14.9$ & 15-29.9 & $30-44.9$ & $\geq 45$ & & \\
\hline \multicolumn{9}{|l|}{ Women } \\
\hline \multicolumn{9}{|l|}{ Total cancer ( $n=19$ 269) } \\
\hline Cases (no) & 3981 & 8176 & 4284 & 1932 & 687 & 209 & - & - \\
\hline Person years (no) & 515558 & 953459 & 495987 & 188987 & 62318 & 17913 & - & - \\
\hline Age adjusted RR $(95 \% \mathrm{Cl})$ & 1 (ref) & 1.05 (1.01 to 1.09$)$ & 1.08 (1.03 to 1.12$)$ & $1.23(1.16$ to 1.29$)$ & $1.40(1.30$ to 1.52$)$ & $1.56(1.36$ to 1.79$)$ & $<0.001$ & 0.004 \\
\hline Multivariable RR $(95 \% \mathrm{Cl})^{\star}$ & 1 (ref) & $1.02(0.98$ to 1.06$)$ & $1.04(1.00$ to 1.09$)$ & $1.13(1.07$ to 1.19$)$ & $1.21(1.12$ to 1.32$)$ & $1.30(1.13$ to 1.50$)$ & $<0.001$ & 0.12 \\
\hline \multicolumn{9}{|l|}{ Alcohol related cancer $(\mathrm{n}=9016) \dagger$} \\
\hline Cases (no) & 1839 & 3762 & 2064 & 914 & 329 & 108 & & \\
\hline Age adjusted RR $(95 \% \mathrm{Cl})$ & 1 (ref) & $1.06(1.00$ to 1.12$)$ & $1.14(1.07$ to 1.21$)$ & 1.27 (1.17 to 1.38$)$ & 1.45 (1.29 to 1.64$)$ & $1.71(1.41$ to 2.08$)$ & $<0.001$ & $<0.001$ \\
\hline Multivariable RR $(95 \% \mathrm{Cl})^{\star}$ & 1 (ref) & 1.04 (0.99 to 1.11$)$ & 1.13 (1.06 to 1.20$)$ & 1.24 (1.14 to 1.35$)$ & $1.42(1.25$ to 1.60$)$ & 1.66 (1.36 to 2.02$)$ & $<0.001$ & $<0.001$ \\
\hline \multicolumn{9}{|l|}{$\begin{array}{l}\text { Alcohol related cancer without } \\
\text { breast cancer }(n=1972)\end{array}$} \\
\hline Cases (no) & 429 & 822 & 414 & 190 & 83 & 34 & & \\
\hline Age adjusted RR $(95 \% \mathrm{Cl})$ & 1 (ref) & 1.01 (0.89 to 1.13$)$ & 0.99 (0.86 to 1.13$)$ & 1.11 (0.94 to 1.32$)$ & $1.56(1.23$ to 1.97$)$ & 2.29 (1.61 to 3.25$)$ & $<0.001$ & 0.63 \\
\hline Multivariable RR $(95 \% \mathrm{Cl})^{\star}$ & 1 (ref) & 1.01 (0.90 to 1.14$)$ & 1.00 (0.87 to 1.15$)$ & $1.08(0.90$ to 1.29$)$ & $1.40(1.10$ to 1.78$)$ & 1.99 (1.39 to 2.84) & $<0.001$ & 0.44 \\
\hline \multicolumn{9}{|l|}{ Other cancer ( $\mathrm{n}=10$ 253) } \\
\hline Cases (no) & 2142 & 4414 & 2220 & 1018 & 358 & 101 & & \\
\hline Age adjusted RR (95\% Cl) & 1 (ref) & 1.03 (0.98 to 1.09$)$ & $1.02(0.96$ to 1.09$)$ & $1.18(1.10$ to 1.28$)$ & $1.36(1.22$ to 1.52$)$ & $1.43(1.17$ to 1.74$)$ & $<0.001$ & 0.91 \\
\hline Multivariable RR $(95 \% \mathrm{Cl})^{\star}$ & 1 (ref) & 1.00 (0.95 to 1.06$)$ & 0.97 (0.91 to 1.03 ) & 1.03 (0.96 to 1.12) & 1.06 (0.95 to 1.19$)$ & 1.06 (0.87 to 1.30$)$ & 0.29 & 0.07 \\
\hline \multicolumn{9}{|l|}{ Men } \\
\hline \multicolumn{9}{|l|}{ Total cancer $(n=7571) \ddagger$} \\
\hline Cases (no) & 1271 & 1998 & 2127 & 1221 & 640 & 314 & & \\
\hline Person years (no) & 166243 & 253036 & 261613 & 138955 & 60721 & 30063 & & \\
\hline Age adjusted RR $(95 \% \mathrm{Cl})$ & 1 (ref) & 1.04 (0.97 to 1.12$)$ & 1.08 (1.01 to 1.16$)$ & 1.14 (1.05 to 1.23$)$ & $1.32(1.20$ to 1.46$)$ & 1.34 (1.18 to 1.52$)$ & $<0.001$ & 0.002 \\
\hline Multivariable RR $(95 \% \mathrm{Cl})^{\star}$ & 1 (ref) & 1.03 (0.96 to 1.11$)$ & 1.05 (0.97 to 1.12$)$ & 1.06 (0.98 to 1.15$)$ & 1.15 (1.04 to 1.27$)$ & 1.13 (0.99 to 1.28$)$ & 0.006 & 0.31 \\
\hline \multicolumn{9}{|l|}{ Alcohol related cancer $(n=1611) \dagger$} \\
\hline Cases (no) & 269 & 381 & 426 & 282 & 161 & 92 & & \\
\hline Age adjusted RR $(95 \% \mathrm{Cl})$ & 1 (ref) & 0.96 (0.82 to 1.12$)$ & 1.04 (0.89 to 1.21$)$ & 1.28 (1.08 to 1.52$)$ & $1.60(1.31$ to 1.95$)$ & 1.89 (1.49 to 2.41$)$ & $<0.001$ & 0.001 \\
\hline Multivariable RR $(95 \% \mathrm{Cl})^{\star}$ & 1 (ref) & 0.98 (0.83 to 1.15$)$ & $1.06(0.90$ to 1.24$)$ & $1.26(1.06$ to 1.50$)$ & $1.48(1.21$ to 1.81$)$ & 1.62 (1.27 to 2.08$)$ & $<0.001$ & 0.004 \\
\hline \multicolumn{9}{|l|}{ Other cancer $(n=5960)$} \\
\hline Cases (no) & 1002 & 1617 & 1701 & 939 & 479 & 222 & & \\
\hline Age adjusted RR $(95 \% \mathrm{Cl})$ & 1 (ref) & 1.07 (0.99 to 1.16$)$ & 1.09 (1.01 to 1.18$)$ & $1.10(1.00$ to 1.20$)$ & $1.25(1.12$ to 1.39$)$ & 1.19 (1.03 to 1.38$)$ & $<0.001$ & 0.07 \\
\hline Multivariable RR $(95 \% \mathrm{Cl})^{*}$ & 1 (ref) & 1.05 (0.97 to 1.13$)$ & 1.04 (0.96 to 1.13$)$ & $1.01(0.92$ to 1.11$)$ & $1.07(0.96$ to 1.20$)$ & 1.00 (0.86 to 1.16$)$ & 0.95 & 0.69 \\
\hline \multicolumn{9}{|c|}{$\begin{array}{l}\text { RR=relative risk; ref=reference. } \\
\text { *Adjusted for age, race, height, body mass index, family history of cancer, physical exam in past two years, history of colonoscopy or sigmoidoscopy, smoking in pack years, physical activity, } \\
\text { regular aspirin use, multivitamin use, total energy intake (without alcohol), red and processed meat intake, alternate healthy eating index } 2010 \text { (without alcohol); prostate specific antigen test } \\
\text { in past two years (men only); and menopause status, postmenopausal hormone use, and mammogram in past two years (women only). } \\
\text { tIncluded cancers of the colorectum, breast (for women), oral cavity, pharynx, larynx, liver, and esophagus. } \\
\text { fFor prostate cancer, only advanced cases were included. } \\
\text { §Calculated using continuous alcohol consumption. }\end{array}$} \\
\hline
\end{tabular}

leading alcohol related cancer in women, whereas colorectal cancer was the major alcohol associated cancer in men. Among women, even an alcohol consumption of 5-14.9 g/day was associated with an increased risk of these cancers (relative risk 1.13 (95\% confidence interval 1.06 to 1.20 ), primarily driven by breast cancer (table 2), and similar for never and ever smokers (fig 2, web table S8) after controlling for obesity and other covariates.

By contrast, risk of alcohol related cancers increased among light and moderate male drinkers who ever smoked $\left(\mathrm{P}_{\text {trend }}=0.006\right)$ but not among those who never smoked $\left(P_{\text {trend }}=0.18\right)$. Consumption of at least $30 \mathrm{~g} /$ day of alcohol was more strongly associated with risk of cancer among ever than never smokers $\left(\mathrm{P}_{\text {interaction }}=0.06\right.$ for women and 0.03 for men). The association between alcohol and alcohol related cancers was also stronger for ages 65 and above and for those with a family history of colorectal cancer, although interactions were not significant. No association between alcohol consumption and risk of other cancers was detected (table 2).
Regularity of drinking and heavy episodic drinking were weakly associated with increased risk of total cancer, although the associations were not significant after adjusting for cumulative alcohol consumption (table 3). Joint analyses of total alcohol consumption and drinking patterns suggested that total alcohol consumption drives the association with risk of cancer (web tables S9 and S10). For alcohol related cancers, increased frequency of drinking was associated with increased risk in men but not in women (web table S11), whereas heavy episodic drinking was associated with increased risk of alcohol related cancer in women but not in men after adjusting for total alcohol (web table S12).

\section{Discussion}

\section{Principal findings}

In two large prospective cohort studies in the USA, the Nurses' Health Study (NHS) and Health Professionals Follow-up Study (HPFS), we quantified risk of cancer 

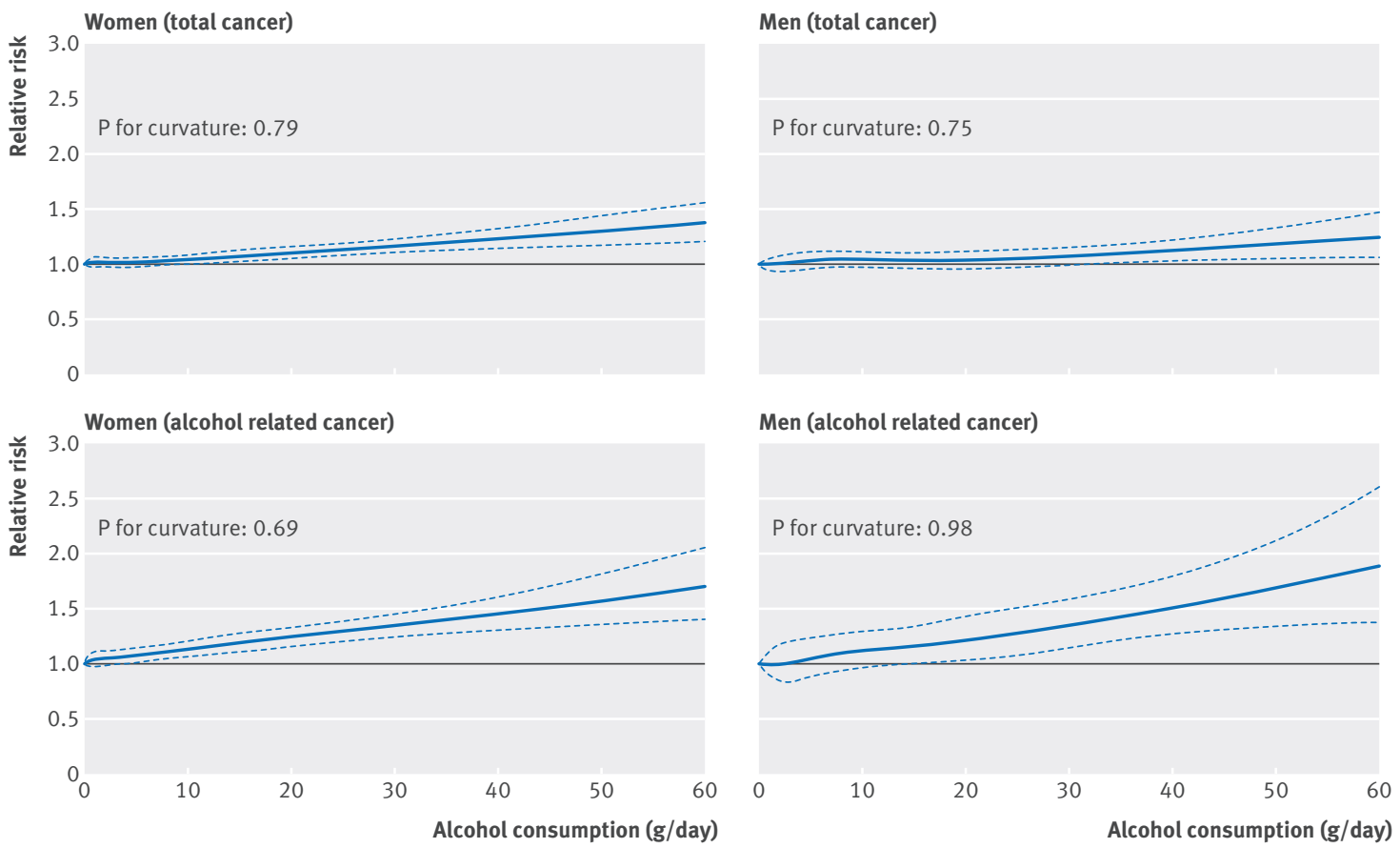

Fig 1 | Non-parametric regression curves showing the association between alcohol consumption and risk of cancer (total and alcohol related). Blue lines=relative risk; dotted lines $=95 \%$ confidence intervals

across all levels of alcohol consumption among women and men separately, with a focus on light to moderate drinking and never smokers. Overall, light to moderate drinking (alcohol intake of $<15 \mathrm{~g} /$ day for women and $<30 \mathrm{~g}$ /day for men) was associated with a small but non-significant increase in cancer risk in both women and men. For men, the association with alcohol related cancers was driven largely by smoking, and light to moderate drinking did not appreciably increase risk in never smokers. Among women, even consumption of
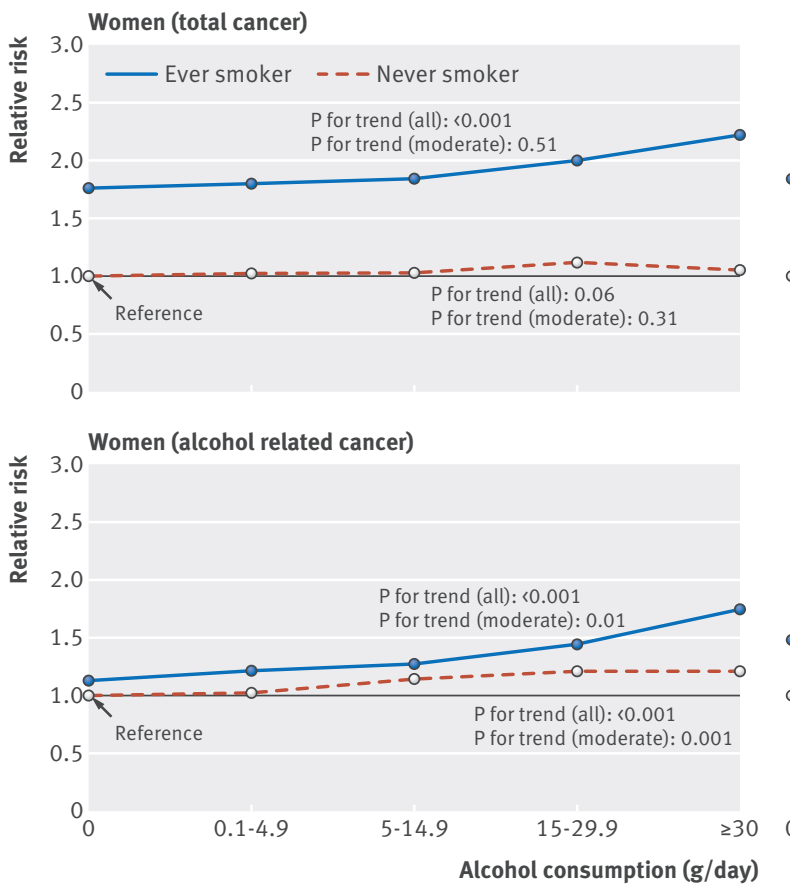

5-14.9 g of alcohol per day was associated with increased risk of alcohol related cancers, mainly breast cancer. Regularity of drinking and heavy episodic drinking was not significantly associated with increased risk of cancer, after adjustment for total alcohol consumption.

\section{Comparison with other studies}

It is estimated that alcohol consumption has caused $3.6 \%$ of all cancers worldwide $1.7 \%$ in women and $5.2 \%$ in men), ${ }^{27}$ and $3.2 \%$ to $3.7 \%$ of cancer deaths in

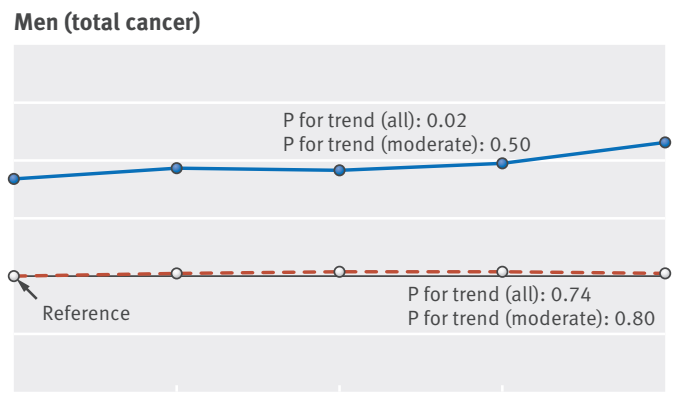

Men (alcohol related cancer)

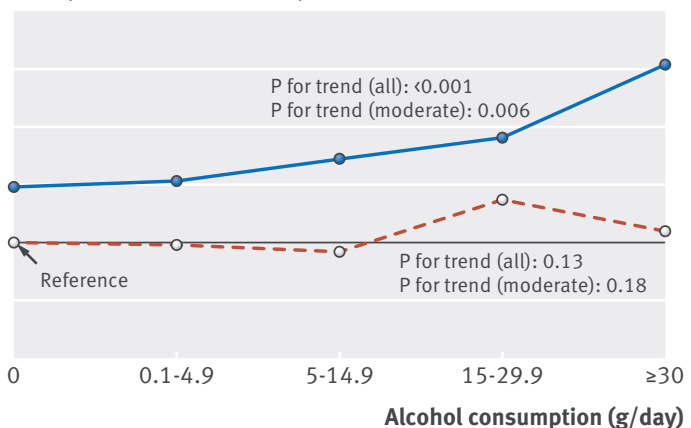

Fig 2 | Risk of total and alcohol related cancer jointly by alcohol consumption and smoking history 


\begin{tabular}{|c|c|c|c|c|c|c|c|c|}
\hline & \multicolumn{4}{|c|}{ Women } & \multicolumn{4}{|l|}{ Men } \\
\hline & $\begin{array}{l}\text { Cases } \\
\text { (no) }\end{array}$ & $\begin{array}{l}\text { Person } \\
\text { years (no) }\end{array}$ & $\begin{array}{l}\text { Multivariable } \\
\text { RR }(95 \% \mathrm{CI})^{*}\end{array}$ & $\begin{array}{l}\text { Multivariable } \\
\text { RR }(95 \% \mathrm{CI}) \dagger\end{array}$ & $\begin{array}{l}\text { Cases } \\
\text { (no) }\end{array}$ & $\begin{array}{l}\text { Person } \\
\text { years (no) }\end{array}$ & $\begin{array}{l}\text { Multivariable } \\
\text { RR }(95 \% \mathrm{CI})^{*}\end{array}$ & $\begin{array}{l}\text { Multivariable } \\
\text { RR }(95 \% \mathrm{CI}) \dagger\end{array}$ \\
\hline \multicolumn{9}{|c|}{ Frequency of drinking (drinks/week) } \\
\hline 0 & 5166 & 512091 & 1 (ref) & 1 (ref) & 1633 & 187897 & 1 (ref) & 1 (ref) \\
\hline $1-2$ & 3069 & 326224 & $1.00(0.96$ to 1.05$)$ & $0.98(0.93$ to 1.03$)$ & 1499 & 187663 & $1.02(0.95$ to 1.10$)$ & 0.99 (0.90 to 1.08) \\
\hline $3-4$ & 1236 & 119744 & 1.03 (0.97 to 1.10$)$ & $1.00(0.93$ to 1.07$)$ & 727 & 90762 & $1.00(0.92$ to 1.10$)$ & $0.95(0.85$ to 1.07$)$ \\
\hline $5-6$ & 1385 & 112878 & 1.09 (1.03 to 1.17$)$ & 1.02 (0.94 to 1.10$)$ & 826 & 92965 & 1.01 (0.93 to 1.11) & $0.94(0.84$ to 1.07$)$ \\
\hline 7 & 986 & 81299 & 1.08 (1.01 to 1.16$)$ & $0.97(0.88$ to 1.06$)$ & 957 & 84137 & 1.09 (1.00 to 1.19) & 0.99 (0.87 to 1.12$)$ \\
\hline$P_{\text {trend }}{ }^{\ddagger}$ & - & - & $<0.001$ & 0.98 & - & - & 0.10 & 0.72 \\
\hline \multicolumn{9}{|c|}{ Highest no of drinks consumed in 1 day } \\
\hline 0 & 4881 & 453421 & 1 (ref) & 1 (ref) & 1403 & 149861 & 1 (ref) & 1 (ref) \\
\hline $1-2$ & 5969 & 570288 & 1.04 (1.00 to 1.08$)$ & 1.02 (0.97 to 1.07) & 2206 & 231914 & 1.02 (0.95 to 1.09) & 0.98 (0.90 to 1.07$)$ \\
\hline $3-5$ & 2040 & 207471 & 1.06 (1.00 to 1.12) & 0.99 (0.93 to 1.06) & 903 & 103447 & 1.05 (0.96 to 1.15$)$ & 0.97 (0.87 to 1.09) \\
\hline$\geq 6$ & 498 & 44084 & $1.13(1.03$ to 1.24$)$ & $1.05(0.95$ to 1.17$)$ & 224 & 24735 & 1.13 (0.98 to 1.31$)$ & 1.03 (0.87 to 1.22$)$ \\
\hline $\mathrm{P}_{\text {trend }} \S$ & - & - & $<0.001$ & 0.18 & - & - & 0.16 & 0.96 \\
\hline
\end{tabular}

$\mathrm{RR}=$ relative risk; ref=reference.

${ }^{*}$ Adjusted for the same covariates as listed in table 2.

tAdjusted for total alcohol intake.

$\ddagger$ Calculated using continuous days of alcohol consumption.

$\S$ Calculated using the median of each category as a continuous variable.

the USA. ${ }^{28}$ These estimates were primarily based on relative risks from studies focused on high intake of alcohol. Indeed, few prospective studies have examined the association of light to moderate alcohol consumption, the most prevalent levels of alcohol intake, with risk of total cancer. Our findings that light to moderate alcohol drinking was not appreciably associated with risk of total cancer in women and men was consistent with findings from women in the British Million Women study. ${ }^{7}$

We also found that alcohol consumption above moderate levels was more strongly associated with risk of cancer among ever smokers than among never smokers. This suggests that the independent influence of alcohol on cancer risk could be limited to populations such as the USA, where the prevalence of smoking is steadily decreasing and light and moderate drinking is prevalent. Indeed, a large consortium analysis has suggested that among never smokers, the association between alcohol consumption and the risk of head and neck cancer is apparent only at high doses (at least three drinks per day), and confined to pharyngeal and laryngeal cancers. ${ }^{29}$

The Million Women Study researchers also found that increasing alcohol intake was associated with an increased risk of cancers of the upper aerodigestive tract among current smokers but not among never smokers. ${ }^{7}$ However, among both never and ever smoking women, an increase in risk of alcohol related cancers, mainly breast cancers, was observed for up to one drink of alcohol per day, which was consistent with findings from our previous analysis on breast cancer as well as the British Million Women study that moderate alcohol intake was associated with a modest increased risk of breast cancer. ${ }^{7} 30$

Genetic predisposition should also be taken into account when discussed individually on the most appropriate levels of drinking. Although we have limited information on family history of these cancers, we observed stronger association of alcohol intake and overall cancer among people who had a family history of colorectal cancer $^{31}$ but minimal differences among people with versus without family history of breast cancer.

\section{Potential mechanisms}

Acetaldehyde, the first and most toxic ethanol metabolite, is considered a cancer causing agent. ${ }^{32}$ Ethanol could also stimulate carcinogenesis by inhibiting DNA methylation and interacting with retinoid metabolism. Bacterial microbiota contributes to the metabolism of alcohol and could mediate many disease promoting and genotoxic effects of alcohol, ${ }^{33}$ in particular for colorectal cancer, ${ }^{34}$ as well as cancers of the oral cavity, where saliva acetaldehyde was found to be high for increasing ethanol intake and where further metabolism of acetaldehyde is limited. ${ }^{35}$ Breast tissue might be more susceptible to alcohol than other organs. Probable explanations involve increased estrogen and androgen levels. ${ }^{30} 36$

\section{Strengths and limitations of the study}

Study strengths included detailed prospective and updated assessment of alcohol consumption, including both quantity and drinking patterns, long term follow-up, and large number of participants to examine association by smoking history and other risk profiles, as well as parallel assessment in women and men. Limitations included self reported alcohol use, but this has previously been shown to be highly reproducible within our cohorts and strongly correlated with levels of high density lipoprotein cholesterol. ${ }^{24}$ Furthermore, measurement error does not substantially affect estimates of the alcohol association. ${ }^{37}$ In addition, since health professionals are generally health conscious, we had limited power to fully evaluate the influence of binge drinking and extremely high levels of alcohol consumption on risk of cancer, as well as risk among current smokers. Finally, residual confounding could not be excluded.

\section{Conclusions}

In summary, our study provides a comprehensive assessment of the relation between alcohol intake, 
including quantity and drinking patterns, and risk of cancer, with a focus on light to moderate drinking and never smokers. Light to moderate drinking is associated with small and non-significant increased risk of overall cancer. For men, the association with alcohol related cancers was primarily observed among smokers, and light to moderate drinking did not appreciably increase risk in never smokers. Among women, even consumption of up to one drink per day was associated with increased risk of alcohol related cancers (mainly breast cancer). Decisions on levels of alcohol consumption should also incorporate information on smoking history and familial predispositions to alcohol related cancers. We thank the participants and staff of the Health Professionals Follow-up Study and the Nurses' Health Study for their valuable contributions, as well as the following US state cancer registries for their help: AL, AZ, AR, CA, CO, CT, DE, FL, GA, ID, IL, IN, IA, KY, LA, ME, MD, MA, MI, NE, NH, NJ, NY, $\mathrm{NC}, \mathrm{ND}, \mathrm{OH}, \mathrm{OK}, \mathrm{OR}, \mathrm{PA}, \mathrm{RI}, \mathrm{SC}, \mathrm{TN}, \mathrm{TX}, \mathrm{VA}, \mathrm{WA}$, and WY.

Contributors: YC and ELG had full access to all of the data in the study and take responsibility for the integrity of the data and the accuracy of the data analysis. YC and ELG conceived and designed the study. WCW, EBR, MIS, and ELG acquired the data. YC and ELG drafted the manuscript. All the authors critically revised the manuscript for important intellectual content. YC carried out the statistical analysis. WCW, EBR, MIS, and ELG obtained funding. YC and ELG were responsible for administrative, technical, or material support. ELG was responsible for study supervision. YC is guarantor. The authors assume full responsibility for analyses and interpretation of these data.

Funding: This work was supported by grants from the US National Institutes of Health (UM1 CA186107, P01 CA87969, P01 CA55075, and UM1 CA167552). The sponsors had no role in the design and conduct of the study; collection, management, analysis, and interpretation of the data; preparation, review, or approval of the manuscript; and decision to submit the manuscript for publication.

Competing interests: All authors have completed the ICMJE uniform disclosure form at www.icmje.org/coi disclosure.pdf and declare: no support from any organization for the submitted work; no financial relationships with any organizations that might have an interest in the submitted work in the previous three years; and no other relationships or activities that could appear to have influenced the submitted work. Ethical approval: The study protocol was approved by the institutional review boards of the Harvard TH Chan School of Public Health and Brigham and Women's Hospital. The completion of the selfadministered questionnaire was considered to imply informed consent. Data sharing: No additional data available.

The lead author (the manuscript's guarantor) affirms that the manuscript is an honest, accurate, and transparent account of the study being reported; that no important aspects of the study have been omitted; and that any discrepancies from the study as planned (and, if relevant, registered) have been explained.

This is an Open Access article distributed in accordance with the Creative Commons Attribution Non Commercial (CC BY-NC 4.0) license, which permits others to distribute, remix, adapt, build upon this work non-commercially, and license their derivative works on different terms, provided the original work is properly cited and the use is noncommercial. See: http://creativecommons.org/licenses/by-nc/4.0/.

1 Baan R, Straif K, Grosse Y, et al. Carcinogenicity of alcoholic beverages. Lancet Oncol 2007;8:292-3.

2 Tramacere I, Negri E, Pelucchi C, et al. A meta-analysis on alcohol drinking and gastric cancer risk. Ann Oncol 2012;23:28-36.

3 Bagnardi V, Rota M, Botteri E, et al. Alcohol consumption and site-specific cancer risk: a comprehensive dose-response meta-analysis. Br J Cancer 2015;112:580-93.

4 Tramacere I, Scotti L, Jenab M, et al. Alcohol drinking and pancreatic cancer risk: a meta-analysis of the dose-risk relation. Int J Cancer 2010;126:1474-86

5 Freudenheim JL, Ritz J, Smith-Warner SA, et al. Alcohol consumption and risk of lung cancer: a pooled analysis of cohort studies. Am / Clin Nutr 2005;82:657-67.

6 Marshall TA. Dietary guidelines for Americans, 2010: an update. J Am DentAssoc 2011:142:654-6.

7 Allen NE, Beral V, Casabonne D, et al. Moderate alcohol intake and cancer incidence in women. J Natl Cancer Inst 2009;101:296-305.

8 Bagnardi V, Rota M, Botteri E, et al. Light alcohol drinking and cancer: a meta-analysis. Ann Oncol 2013:24:301-8.
9 World Cancer Research Fund/American Institute for Cancer Research. Food, nutrition, physical activity, and the prevention of cancer: a global perspective. 2007. www.dietandcancerreport.org/cancer resource_center/downloads/Second_Expert_Report_full.pdf.

10 Ronksley PE, Brien SE, Turner BJ, Mukamal KJ, Ghali WA. Association of alcohol consumption with selected cardiovascular disease outcomes: a systematic review and meta-analysis. BMJ 2011;342:d671.

11 Djousse L, Gaziano JM. Alcohol consumption and heart failure: a systematic review. Curr Atheroscler Rep 2008;10:117-20.

12 Padilla H, Gaziano JM, Djousse L. Alcohol consumption and risk of heart failure: a meta-analysis. Phys Sportsmed 2010;38:84-9.

13 Reynolds K, Lewis LB, Nolen JDL, Kinney GL, Sathya B, He J. Alcohol consumption and risk of stroke-a meta-analysis. IAMA 2003;289:579-88.

14 Koppes LL, Dekker JM, Hendriks HF, Bouter LM, Heine RJ. Moderate alcohol consumption lowers the risk of type 2 diabetes: a meta-analysis of prospective observational studies. Diabetes Care 2005:28:719-25

15 Di Castelnuovo A, Costanzo S, Bagnardi V, Donati MB, lacoviello L, de Gaetano G. Alcohol dosing and total mortality in men and women an updated meta-analysis of 34 prospective studies. Arch Intern Med 2006;166:2437-45.

16 Corrao G, Bagnardi V, Zambon A, La Vecchia C. A meta-analysis of alcohol consumption and the risk of 15 diseases. Prev Med 2004:38:613-9.

17 Latino-Martel P, Arwidson P, Ancellin R, et al. Alcohol consumption and cancer risk: revisiting guidelines for sensible drinking. CMA/2011;183:1861-5.

18 World Health Organization. Global status report on alcohol and health 2014. 2014. http://apps.who.int/iris/bitstream/10665/ 112736/1/9789240692763_eng.pdf.

19 Blot WJ, McLaughlin JK, Winn DM, et al. Smoking and drinking in relation to oral and pharyngeal cancer. Cancer Res 1988;48:3282-7.

20 Petti S, Masood M, Scully C. The magnitude of tobacco smoking-betel quid chewing-alcohol drinking interaction effect on oral cancer in South-East Asia. A meta-analysis of observational studies. PloS One 2013;8:e78999.

21 Gandini S, Botteri E, lodice S, et al. Tobacco smoking and cancer: a meta-analysis. Int / Cancer 2008:122:155-64.

22 Botteri E, lodice S, Bagnardi V, Raimondi S, Lowenfels AB, Maisonneuve P. Smoking and colorectal cancer: a meta-analysis. IAMA 2008;300:2765-78.

23 Jamal A, Agaku IT, O'Connor E, King BA, Kenemer JB, Neff L. Current cigarette smoking among adults-United States, 2005-2013. MMWR Morb Mortal Wkly Rep 2014;63:1108-12.

24 Giovannucci E, Colditz G, Stampfer MI, et al. The assessment of alcohol consumption by a simple self-administered questionnaire. Am J Epidemiol 1991;133:810-7.

25 McCullough ML, Feskanich D, Stampfer MJ, et al. Diet quality and major chronic disease risk in men and women: moving toward improved dietary guidance. Am J Clin Nutr 2002;76:1261-71.

26 Chiuve SE, Fung TT, Rimm EB, et al. Alternative dietary indices both strongly predict risk of chronic disease. / Nutr 2012:142:1009-18.

27 Boffetta P, Hashibe M, La Vecchia C, Zatonski W, Rehm J. The burden of cancer attributable to alcohol drinking. Int J Cancer 2006;119:884-7.

28 Nelson DE, Jarman DW, Rehm J, et al. Alcohol-attributable cancer deaths and years of potential life lost in the United States. Am I Public Health 2013;103:641-8

29 Hashibe M, Brennan P, Benhamou S, et al. Alcohol drinking in never users of tobacco, cigarette smoking in never drinkers, and the risk of head and neck cancer: pooled analysis in the International Head and Neck Cancer Epidemiology Consortium. J Natl Cancer Inst 2007;99:777-89.

30 Chen WY, Rosner B, Hankinson SE, Colditz GA, Willett WC. Moderate alcohol consumption during adult life, drinking patterns, and breast cancer risk. JAMA 2011;306:1884-90.

31 Cho E, Lee JE, Rimm EB, Fuchs CS, Giovannucci EL. Alcohol consumption and the risk of colon cancer by family history of colorectal cancer. Am J Clin Nutr 2012;95:413-9.

32 Seitz HK, Stickel F. Molecular mechanisms of alcohol-mediated carcinogenesis. Nat Rev Cancer 2007:7:599-612.

33 Schwabe RF, Jobin C. The microbiome and cancer. Nat Rev Cancer 2013;13:800-12

34 Seitz HK, Simanowski UA, Garzon FT, et al. Possible role of acetaldehyde in ethanol related rectal cocarcinogenesis in the rat. Gastroenterology 1990;98:406-13.

35 Homann N, Jousimies-Somer H, Jokelainen K, Heine R, Salaspuro M. High acetaldehyde levels in saliva after ethanol consumption: methodological aspects and pathogenetic implications. Carcinogenesis 1997;18:1739-43.

36 Singletary KW, Gapstur SM. Alcohol and breast cancer: review of epidemiologic and experimental evidence and potential mechanisms. JAMA 2001;286:2143-51.

37 Rosner BA. Measurement error models for ordinal exposure variables measured with error. Stat Med 1996:15:293-303.

(c) BMJ Publishing Group Ltd 2015

Web appendix: Supplementary materials 